\title{
LA NATURALEZA DEL EMBRIÓN HUMANO: LA FASE DE PREIMPLANTACIÓN, UN DEBATE ABIERTO
}

\author{
JAVIER DE LA TORRE \\ Universidad Pontificia Comillas (Madrid)
}

\begin{abstract}
RESUMEN: Este artículo pretende exponer la complejidad del tema del estatuto del embrión en la fase de preimplantación. Para ello, se exponen de modo sistemático las diferentes razones que sustentan tanto la postura de la anidación como de la fecundación. Estas razones son tan fundantes que obligan a seguir manteniendo un diálogo abierto y no sustentar posturas cerradas.
\end{abstract}

PALABRAS CLAVE: embrión, anidación, fecundación, diálogo.

\section{The nature of the human embryo: The pre-implantation phase, an open debate}

ABSTRACT: This article wants to show the complexity of the issue of the status of the embryo at the preimplantation stage. To do this, are discussed systematically different reasons behind the nesting position and fertilization position. These reasons are so foundational that we must continue to maintain an open dialogue.

KEY WORDS: embryo, nesting, fertilization, dialogue.

\section{Tema FundamentaL}

Estamos ante un tema complejo. Esta complejidad no debe llevarnos a dejarlo a un lado y menos aún a abandonarnos a un relativismo que abdica de pensar la complejidad.

Es un tema fundante. La respuesta que le demos a esta pregunta condicionará nuestra postura ante la FIV, los bancos de embriones, la manipulación genética, el diagnóstico genético preimplantacional, la clonación, la anticoncepción postcoital, etc.

La metodología para abordarlo no puede ser simplemente deductiva. Desde la aclaración conceptual, luego en un segundo momento, tomar en cuenta las aplicaciones y las consecuencias. Las consecuencias y las aplicaciones iluminan parcialmente los conceptos. Los datos científicos son inevitablemente interpretados a partir de concepciones antropológicas diferentes. Nuestras opciones éticas no se basan sólo en datos biológicos. Son necesarios juicios mixtos, que unan contenidos empíricos y normativos, consideraciones biológicas y antropológicas-filosóficas. «Pero puesto que tanto en la percepción de los hechos como en la descripción de los mismos ya están presentes unos presupuestos previos, constituidos por los paradigmas que nos permiten ver y por los conceptos mentales que nos permiten describir, la realidad percibida estará siempre circunscrita necesariamente dentro de la subjetividad. Esto no quiere decir que los datos aportados no sean ciertos sino lo que significa es que son ciertos dentro del contexto en que fueron elaborados» ${ }^{1}$.

Creo que podemos partir de la afirmación que con la fecundación comienza una nueva vida y que esa vida es humana, que con la fecundación tiene un programa específicamente humano. Es una cuestión ante la que ningún científico debe dudar². La

1 Mayor, F. y Alonso Bedate, C. (2003), Genética. Barcelona: Ariel, p. 20.

2 Lacadena, J. R. (1989), «Estatuto del embrión previo a su implantación», en Abel, F., Boné, E. Y Harvey, J. (eds.) (1989), La vida humana. Origen y desarrollo. Madrid y Barcelona: Universidad P. Comillas e Instituto Borja, p. 36. 
cuestión es si en sus primeras horas y días es una vida humana individual y personal. Partimos, por lo tanto, con Javier Gafo, de tres hechos «científicamente incuestionables» respecto al cigoto: 1) es un ser vivo, un organismo vivo; 2) es biológicamente humano; 3) posee la capacidad de dar origen a un recién nacido al que se le atribuye un derecho básico a la vida.

Desde este punto de partida, es importante reconocer que no es lo mismo preguntar una cuestión que otra: ¿Cuándo ha comenzado a existir nueva vida específicamente humana? ¿Cuándo en el desarrollo embrionario nos encontramos ante un nuevo organismo vivo? ¿Cuándo esa vida corresponde a un nuevo individuo humano, llamado a ser persona? ¿Es el embrión humano una persona? ¿Cuándo nos encontramos en el desarrollo embrionario ante un sujeto de derechos que debe respetarse y protegerse? ¿Se le debe absoluto respeto? ¿Cómo valorar las acciones que conlleven la destrucción/ eliminación de esa vida humana personal? ¿cómo valorar las acciones que destruyen la vida individual?

Es evidente que no es lo mismo preguntarse por lo que «hay» que por la «valoración» que merece la mejora, el cuidado o la destrucción de una realidad que desde 1979, Clifford Grobstein llamó «embrión preimplantatorio»³.

La mayoría de los argumentos que se plantean aquí tienen contestación. No hay un argumento conclusivo ni tumbativo que cierre el debate. Por eso, más allá de argumentaciones y contraargumentaciones es importante percibir la cuestión de fondo que está en juego. Es necesario superar la dialéctica de la confrontación para llegar a percibir las razones de profundidad que se encuentran más allá de los argumentos y la confrontación. El diálogo en profundidad, como bien señalan Gadamer y Ricoeur, supone algo más que oponer opiniones y que sumar o agregar opiniones, implica una transformación de la opinión del uno y del otro ${ }^{4}$. Por eso, expondremos los argumentos intentando ir de la oposición a la transformación de las posturas.

Abordaremos en este artículo un diálogo en profundidad, sobre todo y ante todo, entre las postura genómica y nidatoria. Estableceremos para ello dos decálogos de reflexiones que tienen que entenderse de forma dialogada, una junto a la otra, no en confrontación, no como mera agregación o suma.

\section{La ANidación}

La anidación es un proceso que empieza a tener lugar entre el $6^{\circ}$ y $7^{\circ}$ día y se completa sobre $9^{\circ}$. En el día $14^{\circ}$ está ya constituida la pared endometrial por encima del embrión implantado. A los 6 o 7 días comienza a emitir unas pequeñas raíces o villi, con las que anida o se implanta en el endometrio.

Varias razones y argumentos tienden a dar relevancia moral a este momento.

1- Gemelación. Hasta la anidación hay posibilidad de división del nuevo ser (dando lugar a gemelos monocigóticos idénticos, 1 de cada 500) o fusión de dos embriones (quimerismo) en un mismo embrión. No es «ni uno, ni único» pues puede dividirse en dos o fundirse en uno ${ }^{5}$. La individualidad no está definitivamente determinada hasta

\footnotetext{
3 Grobstein, C. (1979), «External Human Fertilization», Scientific American, 240 (6), pp. 57-67.

4 Gadamer, H. G. (1992), Verdad y método. Salamanca: Sígueme, pp. 184-185.

5 Lacadena, J. R. (1986), "Status del embrión previo a su implantación», en J. Gafo (ed.) (1986), Dilemas éticos de la medicina actual. Madrid: Universidad P. Comillas, pp. 397-403.
} 
aproximadamente dos semanas después de la fecundación ${ }^{6}$. Sólo cabe hablar de persona cuando se supera la posibilidad de gemelación. "Si se considera que un óvulo fecundado es una persona, ¿cómo se explica entonces filosófica y teológicamente que, en el caso de rotura por gemelación (posible hasta el día decimocuarto después de la concepción), una persona pueda convertirse en dos personas? ¿Cómo se puede considerar como una persona a una realidad en la que incluso su individualidad no es segura? ${ }^{7}$

Lacadena explica que los que se originan por una separación precoz, tienen sus propios amnios y corión, mientras los que se separan más tardíamente pueden compartir una o ambas membranas. Por consiguiente, se puede establecer una relación entre el tipo de membranas de ambos fetos (monocoriónicos, monoamnióticos o ambas situaciones a la vez) y el tiempo durante el desarrollo en que ocurrió la separación. Por ejemplo, la formación de los gemelos a partir de la separación de los blastómeros tempranos daría lugar a gemelos dicoriónicos; en cambio si el embrión se divide al principio de la segunda semana después de la fecundación, se formarían con toda probabilidad fetos monocoriónicos y diamnióticos. Se estima que dos de cada tres gemelos monocigóticos se originan de esta forma ${ }^{8}$.

Ante el quimerismo, algunos se preguntan que si previamente había dos personas ¿qué ha pasado con una de ellas??

Frente argumento mellizos-quimeras algunos autores contraargumentan afirmando que una bacteria es un individuo que al reproducirse da lugar a otro semejante. Comprenden la gemelación como un proceso de yemación. La gemelación (monocigóticos 2,5 por mil) parece ser que no es la fisión de un cigoto en dos células hijas sino más bien la aparición de una «yema o brote» a partir de un individuo en desarrollo epigenético que sigue su propio desarrollo; las discordancias genéticas entre gemelos monocigóticos apoyan esta afirmación. Puede que la causa bioquímica de la gemelación sean los bajos niveles de calcio que afectan a las interacciones celulares en el estadio embrionario ${ }^{10}$.

Es necesario además, como bien apunta Ford, diferenciar la individualidad genética de la individualidad ontológica en los gemelos. No es mismo lo individualidad que indivisibilidad. No es un embrión que se convierte en dos, sino uno que proviene del otro. Es más bien un proceso de filiación. El individuo no se caracteriza por su indivisibilidad (en potencia). Además no son iguales en el origen aunque haya parecido morfológico en el nacimiento. Uno está en el origen corporal del otro. Pero más allá de este argumento, hay que reconocer que los dos "gemelos» son proyectos humanos, no plantas ni animales y parece que siempre hay un primero que mantiene su existencia e identidad biológica y ontológica aunque transformada o modificada (como un adulto al que se le amputa un brazo) y un segundo que nace del primero. En ambos hay un programa en desarrollo. Más complejo es el quimerismo pues parecería que deja de existir una individualidad.

Algunos responden a esta objeción distinguiendo entre individualidad e indivisibilidad pues, por ejemplo, las bacterias, siendo individuales, son divisibles.

La objeción parece no sólo hacer referencia a una indivisibilidad actual sino también futura. Esto, para algunos, es acertado para los seres humanos adultos. Pero un concepto estático de indivisibilidad no parece adecuado para los primeros procesos de desarrollo que requiere más un concepto más dinámico de indivisibilidad. Entendida

\footnotetext{
GAFo, J. (2003), Bioética teológica. Madrid-Bilbao: Universidad P. Comillas-DDB, p.196.

Thevenot, X. (1985), «Le statur de l'embryon», Projet, 195:45-46.

LACADENA, J. R., art.cit., 38.

Mahoney, J. (1984), Bioethics and Belief. London: Sheed \&Ward, pp. 52-86.

10 Núñez de Castro, I. (2008), De la dignidad del embrión. Madrid: Universidad P. Comillas, pp. 84-89.
} 
dinámicamente, cada uno de los mellizos está predispuesto desde el comienzo para alcanzar su figura final desde la cual se determina su individualidad. Se puede interpretar que al cigoto originario se le agrega por división otro. Un individuo tiene en sí la posibilidad de formar nuevos individuos. Por eso la formación de mellizos puede ser interpretada sin contradecir nuestras representaciones de la individualidad.

Además hay que explicar por qué más del 98\% de los casos no se llega a la formación de mellizos y la individualidad genética implica unidad numérica.

Pero el argumento no debe depender de la frecuencia de un hecho, que de por sí es incontestable. Unicidad e individualidad ocurren después que el organismo genéticamente único se implante ${ }^{11}$.

También hay que preguntarse por qué la posibilidad de mellizos ha de fundamentar una menor protección del embrión originario. Si de una unidad biológica nacen dos individuos humanos, parece hay que proteger esa unidad biológica aunque no comprendamos bien ese proceso.

Otra cuestión a considerar es que todo ser material es cuantitativamente extenso y lo extenso es, por definición, divisible. El «indivisum in se» refiere más a la unidad interna que a la indivisibilidad. Además la indivisibilidad de la sustancia aristotélica hace referencia más a unidad interna (tóde ti) que a que sea indivisible (átomon). Por otro lado hay que reconocer que individuo implica que tiene «algunas partes», no todas, que son imprescindibles, de tal forma que si se seccionan del organismo, el individuo muere.

Finalmente en estas cuestiones creo de enorme interés recordar que Clifford Grobstein menciona seis características propias de la individualidad, que aparecen durante la vida: genética, desarrollo, funcional, conductual, psíquica y social. El cigoto ha adquirido un primer nivel de individualidad, la genética, pero su individualidad no se ha logrado del todo, debido a la posibilidad de originar mellizos de idéntico genotipo. Grobstein afirma que la individualidad de desarrollo se alcanza con el comienzo de la implantación del blastocito en la pared uterina, que a las ocho semanas se perciben leves signos conductuales y que con el nacimiento comienza el individuo desde un punto de vista social ${ }^{12}$.

2- Elevadas pérdidas. El 50-70\% de los óvulos fecundados no llegan a realizar su implantación. Elevado número de abortos espontáneos. Número importante se da en embriones cromosómica o genéticamente anómalos que de continuar su desarrollo originarían niños con graves anomalías o embriones no viables. La anidación parece funcionar como un rubicón que corrige los frecuentes errores que acontecen en el proceso de fecundación y así se evita el nacimiento de niños con malformaciones ${ }^{13}$.

Anne Fagot-Largeault y Geneviève Delaisi de Parseval estiman que dos de cada tres óvulos fecundados mueren durante las primeras seis semanas ${ }^{14}$.

El profesor Elizari se pregunta a raíz de estas elevadas pérdidas: «Si la naturaleza parece ser tan derrochadora, ¿no deberíamos suavizar las reservas para poder interrumpir esa vida tempranamente, cuando su continuación ofrece problemas serios? ¿Es posible que sean seres personales, con destino y vocación eternos, ese número tan elevado de

11 Shannon, T. y Wolter, B. (1990), «Reflections on the moral status of the pre-embryo», Theological Studies 51613.

12 Grobstein, C. (1988), Science and the unborn. New York: Basic Books.

13 Lacadena, J. R. (1985), «Una lectura genética de la sentencia del Tribunal Constitucional sobre el aborto», Jano 29 (1985) n 665, p. 1557.

14 Fagot-Largeault, A. y Delaisi de Parseval, G. (1989), «Qu'est-ce qu'um embryon? Panorame des posicions philosophiques actuelles», Esprit, 95, pp. 86-118. 
vidas cortadas tan prematuramente por la misma naturaleza?» ${ }^{15}$. También Karl Rahner parece pensar que si el 50\% de los seres humanos no sobrepasa a priori nunca el primer estado de la existencia humana esto cuestiona ciertos fundamentos: «Desde hace unos siglos la teología moral católica viene estando convencida de que en el momento de la unión de las células germinales masculina y femenina es también el momento en que un individuo humano deviene a la existencia. ¿Tendrá el teólogo moral contemporáneo el coraje de mantener este presupuesto como base para muchas de sus afirmaciones teológico-morales, cuando confrontado con el conocimiento de que cerca del $50 \%$ de todas las células femeninas fertilizadas no tienen éxito en su implantación uterina? ¿Será capaz de aceptar que el 50\% de todos los seres humanos — seres reales con sus almas "inmortales" y destino eterno - nunca pasarán más allá de este primer estadio de la existencia humana?» ${ }^{16}$. Rahner acepta el dato de la cantidad de embriones que no logran la implantación y apela a la tesis de la animación retardada. El organismo biológico pasa por varias fases que no son todavía plenamente hombre y que no representan todavía una potencia próxima inmediata para la animación espiritual, pero que tampoco pueden ser consideradas sin más como una porción del organismo materno ${ }^{17}$. En el fondo se reconoce que el debate sobre la hominización retardada o inmediata es el equivalente al debate clásico sobre la animación.

Algunos llegan a plantear la cuestión de si no es un criterio de naturalidad la extrema regularidad de las leyes físicas. ¿No sería algo contra natura que el zigoto fuese una persona humana? Algunos contestan que no cabe hablar de naturalidad para referirse a abortos espontáneos. Si fuera natural sería modelo de imitación.

El argumento de las elevadas pérdidas es insuficiente para algunos autores pues es un argumento estadístico, a su juicio comparable con situaciones de elevada mortalidad infantil o perinatal en países pobres o en tiempos pasados ${ }^{18}$. Por sí sólo no tiene fuerza probativa. La cuestión no parece tan fácil de resolver pues la analogía con la elevada mortalidad infantil no parece oportuna pues no parece claro que con una mayor atención y un mayor desarrollo se podrían reducir significativamente las elevadas pérdidas. Otros cuestionan los datos. Wilcox y su equipo informaron de 155 embarazos clínicamente constatables y 136 llevados a término ${ }^{19}$.

Algunos señalan, desde una perspectiva religiosa, que estas vidas que no poseen un mínimo de perfección, pero que Dios puede hacer que el «cuerpo glorioso» tenga todos sus elementos perfeccionados ${ }^{20}$.

Lo que sí tenemos que aceptar es que el embrión preimplantatorio debe ser reconocido por la madre pues la mitad del nuevo genoma es de origen paterno y es extraño a su cuerpo. Este proceso complejo de «tolerancia» explica por qué un número elevado de embriones no llega a anidar en el endometrio.

3- La frontera de los 14 días coincide con la constitución de la línea primitiva, el primer esbozo del sistema nervioso. Las células del epiblasto se organizan a través de la línea primitiva en un individuo humano multicelular, que posee por primera vez un eje

15 Elizari, J. (1994), Bioética. Madrid: San Pablo, p. 129.

16 Rahner, K. (1973) «The problem of genetic manipulation», en Theological Investigations, vol. IX, New York: Herder and Herder, 226 (nota 2). Trad.esp.: RAHNER, K., Escritos de teología, vol XII. Madrid: Cristiandad.

17 Ibid., p. 229.

18 Nuñez de Castro, I. (2008), De la dignidad del embrión. Madrid: Universidad P. Comillas, p. 134.

19 New England Journal of Medicine 1988, 319: 189-194.

20 Caspar, Рн. (1992), «Elements pour une eschatology du zygote», Revue Thomiste 92, 460-481. 
corporal y simetría bilateral. Se arguye que, así como la muerte cerebral es el referente para la muerte de la persona, así también el comienzo de la actividad cerebral sería el comienzo de la vida de la persona. Es decir, para que haya vida humana personal se precisa de un mínimo de substrato biológico humano de la corteza cerebral (que se sitúa entre los 25 a 40 días de gestación).

Un texto esencial y clásico que defiende esta postura es el de N. M. Ford: «La aparición de la línea primitiva es el signo de que un embrión propiamente dicho e individuo humano se ha formado y ha comenzado a existir. Hablar, antes de este estado, de un verdadero ser humano en el sentido ontológico no tiene sentido» ${ }^{21}$

También la Comisión Waller, en Australia, parece defender el peso de este argumento: «No más de 14 días» porque después de este estadio se forma la línea primitiva «y la diferenciación del embrión es evidente»²2. También varios integrantes del Comité Warnock defendían esta idea.

Por el contrario, para algunos como A. Serra, la línea primitiva del embrión es el punto de llegada de un proceso, de acontecimientos concatenados y coordinados, no algo que emerge en un instante.

4- Concebir es ser acogido en paredes del útero, ser concebido. El embrión se implanta, la mujer se queda embarazada, el embrión echa raíces. Fertilización es distinto de concepción para los ginecólogos. Aunque haya una relación entre el embrión preimplantatorio y la madre en los primeros días, sin duda se produce un mayor contacto entre la madre y el embrión con la anidación. Sin anidación, el embrión no puede vivir. No cabe la analogía con el alimento del bebé después del nacimiento (sin alimento el bebé es bebé) pues la madre es algo más que soporte nutritivo. Tampoco quizás puede verse la anidación como una variable del reconocimiento por parte de otros en el sentido de dar cabida en su útero como si el estatus moral del embrión dependiera de una decisión externa. La anidación es algo más que reconocimiento externo es acogida del cuerpo de la mujer, enraizamiento del embrión en la mujer. La anidación es una realidad con un profundo valor simbólico.

Habría que pensar aquí lo que supone de desafío la clonación humana. Que el origen de una vida humana venga por un camino distinto que la unión de un óvulo y un espermatozoide. Esto no sólo abunda en la importancia de distinguir fertilización y concepción sino en considerar a fondo la diferencia entre embriones in vitro e in vivo. No sólo hay que considerar el origen sino el contexto.

5- Totipotencialidad. Si separamos artificialmente los blastómeros provenientes de embriones de 2 y hasta 16 células, estos embriones conservan su totipotencialidad. Esta capacidad se pierde en estadios posteriores. Por eso, podemos hablar en esta etapa de falta de individualización, singularidad, concreción. Sólo en el día $7^{\circ}$, la blástula está diferenciada (embrión y placenta). El individuo completo es un organismo diferenciado e integrado por diversos órganos con diversas funciones. Por eso en estas primeras fases no estamos ante un individuo plenamente constituido y, por lo tanto, ante una persona humana.

21 Ford, N. M. (1988), When Did I Begin? Conception of the Human Individual in History. Cambridge: Cambridge University Press, p. 168.

22 Committee to Consider the Social, Ethical and Legal Issues arising from in Vitro Fertilization, Report of the embryos produced by in Vitro Fertilization, F. D. Atkinson Goberment Printer, Melbourne, 1984. 
Algunos distinguen entre totipotencialidad de blastómeros considerados aisladamente (hasta 8 células) y totipotencialidad del blastocito dentro del embrión que permanece hasta los 15 días (de ahí aparición gemelos) ${ }^{23}$.

Desde esa potencialidad abierta algunos afirman que el embrión preimplanttorio no es todavía un ser humano, un individuo humano. El bloque de mármol es una estatua potencial. El embrión es un hombre potencial cuya mera potencia no fundamenta todavía plenos derechos de protegerlos. Algunos distinguen entre potencialidad fuerte y débil, activa y pasiva. El bloque de mármol únicamente tiene potencia material para ser una estatua. Esto es distinto de la potencia activa del ser viviente existente que puede desarrollarse desde lo que es para llegar a ser algo que todavía no es. El embrión no se desarrolla hacia la condición de ser humano sino desde el comienzo como ser humano.

Ford distingue entre potencial de unas células para transformarse en individuo humano y potencial de un individuo humano para desarrollarse a través de la multiplicación y diferenciación de sus células ${ }^{24}$. En esta fase se está ante un conjunto de células que tienen el potencial de transformarse en individuo humano.

6- Criterio de diferenciación de partes. Hasta la etapa de 8 blastómeros hay muy poca cohesión interna. Cada blastómero absorbe sus nutrientes y posee cierta autonomía, en lo que es más parecido a un conjunto de individuos, que a un único organismo multicelular. Es una masa programada de células con un bajo nivel de organización. Parece difícil hablar de una unidad que «sujete» y «unifique» los diversos blastómeros.

El embrión de cuatro células es pluripotencial (capacidad de transformarse en embrión completo) y totipotencial (capacidad de transformarse en tejido embrionario o de la placenta). No constituye un organismo pues aparentemente no existe relación funcional entre sus células. Una masa de células por sí sola no constituye una vida individual aunque sus células estén vivas y sean humanas ${ }^{25}$. Son humanos en el sentido de tener un genoma humano y por estar vivo. Pero son características insuficientes para calificar al embrión preimplantado como un ser humano vivo.

7- Argumento de la mínima materialidad. Se requiere cierta estabilidad biológica como condición necesaria para la animación. La estabilidad se alcanza por la imposibilidad de gemelación y quimerismo. El «alma» humana requiere un mínimo de materia a la cual fundirse para constituir una persona plena. Durante muchos siglos (VII-XVII) se defendió mayoritariamente la animación no inmediata sino retardada. Se pensaba que el alma humana sólo podía entrar en un cuerpo con forma humana como un inquilino en una casa construida. El alma, para Aristóteles, es el acto primero de un cuerpo organizado. El embrión preimplantatorio no presenta la organización suficiente. Para Aristóteles ni la forma ni la materia pueden existir por sí solas como dos sustancias independientes.

Este argumento vinculado al de la forma-apariencia humana tiene profundo valor antropológico. Se impone con especial fuerza a la sensibilidad. Del s. VII-XVII se pensaba que el feto no estaba plenamente formado (y, por lo tanto, humanizado) hasta los 40 días (Aristóteles, Hipócrates). Influyó también el relato de la creación, por el cual Dios insufla al ser humano el espíritu «después» de la creación del cuerpo. Para muchos no

23 Sica, G. (2008), «El desarrollo del embrión preimplantatorio», en Screccia, E. y LAFFite, J. (eds.) (2008), El embrión humano en fase de preimplantación. Aspectos científicos y consideraciones bioética, BAC: Madrid, pp. 38-47.

24 Ford, N. (1989), When did I begin?. Cambridge: Cambridge University Press, p. 100.

25 Evans, D. (1996), Conceiving the embryo. The Hague: Martinus Nijhoff Publishers, p. 34. 
puede decirse que las teorías escolásticas de la animación sucesiva no tienen valor argumentativo alguno y que sólo tienen un valor histórico ${ }^{26}$. No pueden ser tantos siglos de creencia rechazados por ser precientíficos. Este presupuesto se mantuvo también por la experiencia de la semejanza morfológica de los embriones humanos y animales en sus estadios iniciales. Si bien el aborto nunca se considero algo lícito, sí permaneció un diferente juicio entre el aborto formado e informado. Algunos, como Dietmar Mieth, interpretan los textos de Santo Tomás ${ }^{27}$ sobre la animación retardada señalando que lo importante no es tanto la periodización del ser humano, que la sucesión parezca más «analítica que gradualista». Lo esencial parece ser que la persona humana no se debe a planes humanos sino a la creación de Dios, que lo hace originariamente libre.

8- Importancia del componente feto-materno en el desarrollo humano. La dotación genética y el medio materno son factores «necesarios» aunque cada uno por separado son «insuficientes» para la constitución esencial del nuevo ser. Es imprescindible la existencia de una estructura en parte materna y en parte fetal para que puedan actualizarse las potencialidades del blastocisto. Las profundas transformaciones maternas dinamizadas por el blastocisto no están impresas en el mensaje genético del embrión. La aportación materna en la constitución del nuevo ser es mucho más que un mero soporte nutritivo. La supervivencia del cigoto depende de su implantación uterina. F. Abel señala con claridad: "El obstetra considera el inicio en estadio de blastocisto, cuando un determinado cigoto se implanta en el útero. Antes de esto, el cigoto humano es un programa genético humano con sólo el potencial teórico y estadístico para llegar a ser un miembro de la comunidad humana, puesto que sólo uno de cada tres cigotos llegan a implantarse. ...El obstetra ve claramente que la supervivencia del cigoto depende de su implantación uterina, que no se dará espontáneamente — caso in vitro-» ${ }^{28}$.

9- Hay información extracigótica que es relevante en el desarrollo: la herencia mitrocondrial materna, la interacción entre moléculas, la interacción con la madre. El cigoto no contiene por sí solo toda la información requerida para la génesis de una persona. La información exógena independiente al control del cigoto es determinante en la génesis de la persona. El cigoto no posee en su genoma «toda» la información requerida para la génesis correcta y completa del proceso embriológico: «El cigoto, aunque sea biológicamente perfecto, no posee en sí mismo la determinación absoluta a ser persona humana. Su determinación depende en cada momento 1) de la actualización progresiva de su propia información; 2) de la actualización de informaciones que se originan de nuevo durante el proceso embrionario y 3) de informaciones exógenas independientes del control del cigoto, como célula originaria, o de cada uno de los elementos originados en el proceso...En toda célula existen además multitud de moléculas que tienen una importante actividad informante y que no están codificadas en ningún sitio en el genoma. Ejemplos de tales moléculas son los aminoácidos (algunos de los cuales son neurotransmisores), los lípidos, hidratos de carbono y algunas hormonas» ${ }^{29}$.

26 Schockenhoff, E. (2012), Ética de la vida. Barcelona: Herder, p. 517.

27 Summa Theologiae I, 118, 2

28 Abel, F (1992), "Aspectos éticos de las tecnologías de la reproducción asistida», Actas $12^{\circ}$ curso de verano de San Roque, Universidad de Cadiz, p. 40

29 Alonso Bedate, C. (2005), «Reflexiones sobre cuestiones de vida y muerte: Hacia un nuevo paradigma de comprensión del valor ético de la entidad biológica humana en desarrollo», en F. ABEL, E. BonÉ y J. Harvey (2005), La vida humana. Origen y desarrollo. Madrid y Barcelona: Universidad P. Comillas e Instituto Borja, pp. 65-67. 
Otra evidencia es la hormona T4 materna, necesaria para el desarrollo neural del feto. «Esta hormona se trasvasa, en un determinado momento del desarrollo embrionario, de la madre al embrión por la placenta y se detecta en el embrión antes de que éste pueda expresar su propia T4. Puesto que esta hormona regula la expresión de genes del embrión esenciales para su correcto desarrollo, que anteriormente estaban silenciados, entra a formar parte de la dinámica de desarrollo del embrión ${ }^{30}$. Esto confirma que el sistema cerrado genético del embrión no es condición suficiente para el correcto desarrollo del embrión.

El material genético materno existente en las mitocondrias del óvulo tiene también un importante papel en la expresión del ADN nuclear del embrión.

Por otro lado, es evidente que hay una información que es fruto de la interacción de dos o más moléculas cuyo resultado es una nueva síntesis. Esta información no está codificada en el genoma y se produce como resultado de la interacción del embrión con la madre a partir del proceso de diferenciación.

La consecuencia parece clara:"El cigoto hace posible la existencia de un ser humano pero no tiene, de sí y ni por sí mismo, la suficiente información para formarlo. La constitución del embrión depende de una serie de eventos que ocurrirán durante el transcurso de la ontogénesis, algunos de los cuales están fuera de control del programa genético. El cigoto posee suficiente información para producir exclusivamente tejido humano, pero no para desarrollarse en un ser humano. Esto no significa que el cigoto carezca de valor específico por su relación con la persona a la que puede dar origen, sino que el estatuto del cigoto no puede ser el mismo que el de la persona que llegará a ser „ ${ }^{31}$

La realidad biológica no es definida por su genotipo ni aun por su fenotipo embrionario sino por la realidad emergente. La realidad constituida está dotada de cierta autonomía biológica y tiene una capacidad de diálogo interno entre los elementos aunque el fenotipo no esté finalizado. Los genes además son el resultado de un proceso de ensayo y error del medio. No tienen toda la información que necesita un individuo para constituirse. Es preciso la interacción entre la información genética y la que procede del medio, del protoplasma, de las otras células, de la madre. Sin esta interacción no es posible la expresión de la información genética. No cabe defender una especie de «homúnculo informativo» sin reconocer que la persona se constituye después de la explicitación de las informaciones en un proceso de sucesivas transformaciones.

10- Ausencia de intelección, de psique. Si la persona es un individuo capaz de sufrir, relacionarse, razonar, ejercer la libertad, estas capacidades requieren la presencia del cerebro. Pero el «sistema» nervioso central no empieza a formarse hasta las 6-7 semanas. Para algunos basta el emerger de lo psíquico sobre lo biológico para hablar de persona. La intelección es la nota definitoria, esencial y constitutiva de la humanidad. El embrión, por lo tanto, comienza a ser realidad humana cuando adquiere el fenómeno de la intelección. Pero la intelección es una propiedad sistemática, por lo que la humanidad no se consigue hasta que no se alcanza ese sistema, hasta que no está presente la intelección como nota sistemática. Para algunos, esto ocurre cuando el proceso de formalización nerviosa es muy elevado, y en consecuencia cuando la complejidad estructural y la suficiencia constitucional están muy avanzadas. Para

30 Alonso Bedate, C. (2003), «El estatuto ético del embrión humano: una reflexión ante propuestas alternativas», en Mayor Zaragoza, F. y Alonso Bedate, C. (coords.) (2003), Gen-ética. Barcelona: Ariel, p. 39.

31 Alonso Bedate, C. y Cefalo. R. (1990), «El cigoto: ser o no ser de una persona», Labor Hospitalaria 22, n n $^{\circ} 17$, pp. 231-233. 
otros con el comienzo de actividad eléctrica (43-45 días). Finalmente otros este argumento lo utilizan de forma débil: cuando emerge la línea primitiva (15 días). La capacidad de ejercer la racionalidad implica, por lo tanto, para algunos la existencia de un mínimo de estructuras orgánico fisiológicas para posibilidad su ejercicio. Ese criterio de mínima racionalidad unos lo ponen en la formación del tubo neural, otros en las primeras respuestas reflejas y otros cuando se tiene un sistema nervioso integrado.

Un ejemplo podría ser el de «Yo no sé cuándo es infundida el alma en el cuerpo, pero estoy seguro de que no hay alma humana y, por esto mismo, de que no hay persona humana en las primeras semanas de embarazo (...) Lo mínimo que se puede pedir antes de admitir la presencia del alma humana es la disponibilidad de estos órganos: los sentidos, el sistema nervioso, el cerebro y especialmente la corteza cerebral. Puesto que estos órganos no están preparados durante los primeros días del embarazo, estoy seguro de que no hay persona sino después de varias semanas» ${ }^{32}$.

Hay, según algunos autores, en el fondo una cierta metafísica deductiva. Es decir, los principios metafísicos son deducidos desde la capacidad racional de la inteligencia sentiente. Se buscan primero las condiciones para que se pueda darse la presencia de un principio espiritual o un principio estructural en el cuerpo (para algunos basta la presencia de ciertos esbozos de estructuras que permiten que la inteligencia se pueda actualizar). Hay un cierto dualismo en esta forma de argumentar. Un cuerpo en que se infunde el alma, una estructura en un cuerpo.

Esta concepción parece influir en un teólogo de la altura de B. Häring: «El argumento de que la mórula no puede ser todavía una persona o un individuo con todos los derechos de la especie humana me parece convincente mientras sigamos nuestro concepto tradicional de persona ${ }^{33}$.

Hay que recordar finalmente que la línea primitiva no aparece de repente sino dentro del conjunto del proceso de desarrollo y desde determinadas células que originarán las laminillas que constituyen la línea primitiva embrionaria. La racionalidad es un proceso dinámico que se encuentra ya programado en la información genética del cigoto $^{34}$.

\section{La Fecundación}

Analizaremos los principales argumentos en torno a la fecundación como momento clave para hablar de individuo humano y persona humana.

1- La fusión de los gametos implica ya un código genético propio distinto del de los progenitores. Aparece una realidad biológica humana nueva con sus 32.000 genes. Dos células altamente especializadas, el óvulo y el espermatozoide, dos sistemas autónomos, dan lugar a un nuevo sistema con una información genética cualitativamente distinta de las células somáticas del organismo paterno y materno. Es un nuevo sistema y no una suma de dos subsistemas. La nueva combinación del genoma individual a partir

32 Doncel, J. F. (1970), «Immediate animation and delayed hominization», Theological Studies 31, 106.

33 Häring, B. (1976), «New Dimensions of Responsible Parenthood», Theoligical Studies 37, 127.

34 Lacadena, J. R. (1995), "Consideraciones genético-biológicas sobre el desarrollo embrionario humano», en Romeo-Casabona, C. (ed.) (1995), Genética humana. Bilbao: Universidad de Deusto-Fundación BBV, pp. 77-103. 
de la parte materna y paterna según el principio de aleatoriedad, hace nacer de manera prodigiosa un nuevo ser humano. No hay transición gradual sino un nuevo comienzo radical. El nuevo genoma humano parece tomar la función que tenía la sustancia en la teoría hilemófica. Es un nuevo proyecto-programa individualizado, una nueva vida individual, una nueva entidad ${ }^{35}$. Con la fecundación se da la última posibilidad de entrecruzamiento genético entre el material materno y paterno.

2- Identidad. En el cigoto se "prefigura» el individuo humano que se va a desarrollar. Es un nuevo proyecto-programa. Cada ser humano (excepto los gemelos monocigóticos) es único e irrepetible. Hay que afirmar que la carga genética tiene un influjo básico y que está marcada desde la fecundación. Hay unos caracteres hereditarios que lo acompañarán durante toda la vida. No existe sólo como un ser humano, sino como éste ser humano singular, único e inconfundible ${ }^{36}$.

3- Tras la fusión de los gametos se inicia el ciclo vital de un «nuevo sujeto humano» ${ }^{37}$. El embrión no es un apéndice. Es una realidad ontológicamente distinta. Desde le principio comienza a dirigir su propio proceso de desarrollo, sintetizando sus propias proteínas y enzimas, que son distintas de las de su madre. Es sumamente dependiente pero también es autónomo. Dirige su propio proceso de desarrollo, es «arquitecto» de sí mismo. Posee en su código genético los «planos» de lo que él mismo va a ser y organiza mediante la síntesis de sus propias proteínas y enzimas su propio proceso de construcción. La madre le proporciona el material alimenticio y energético pero el mismo dirige su desarrollo ${ }^{38}$. Posee en sí el potencial para desarrollarse como adulto y no necesita de información molecular adicional de la madre. El nuevo ser tiene ya en germen su propio poder de crecimiento y reproducción. Actúa como un sistema que se organiza a sí mismo y que se mueve hacia el objetivo de su figura final. Las diferencias respecto a los estados ulteriores son meramente cuantitativas. El nuevo ser tiene su propia red de comunicación y envía al cuerpo de la madre información hormonal. El nuevo genoma asume el control de todo el proceso epigenético desde los primeros estadios de desarrollo. En el paso de 4 a 8 células, el nuevo genoma se muestra activo en el control de las nuevas proteínas y al memos ocho genes están activos desde el estadio de cigoto (estudios de P. Braude, V. Bolton y S. Moore). El nuevo genoma es el sostén constante de la unidad estructural y funcional del embrión que se desarrolla en una dirección constante.

4- Hay una continuidad en el proceso de desarrollo embrionario. La embriología habla de un proceso continuo en el que se van actualizando de forma gradual y continua todas las potencialidades ya presentes en el cigoto. Todo intento de marcar fronteras suscita el interrogante de la artificialidad de tal frontera ${ }^{39}$. Hay una especie de efecto cascada: la replicación celular, la determinación celular, la diferenciación de los tejidos, la formación de los órganos... son pasos sucesivos ${ }^{40}$. Hay una continuidad ininterrumpi-

35 Sgreccia, E. (1996), Manual de Bioética. México: Diana, p. 337.

36 Gafo, J. (2003), Bioética teológica. Madrid: Universidad P. Comillas, pp. 194-195.

37 Serra, A. (2006) «Dignidad del embrión humano» en AA. VV. (2006), Lexicon. Pontificio Consejo para la Familia. Madrid: Palabra, p. 270.

38 GAFO, J. (2003), op. cit., p. 195.

39 GAFO, J. (2003), op. cit., p. 196.

40 "La información genética en el cigoto humano determina qué moléculas serán formadas; éstas a su vez determinan qué proteínas y enzimas se formarán y éstas determinan qué tejidos y órganos serán 
da del proceso de progresiva diferenciación del individuo concreto y determinado. Hay un proceso continuo de formas más simples a formas más complejas. La continuidad implica la unicidad o singularidad del nuevo sujeto. Desde la singamia se trata del mismo e idéntico individuo humano que va pasando por estadios cualitativamente más complejos. Hasta el Comité Warnock lo reconoció claramente: «Una vez que se ha iniciado el proceso, no existe parte alguna de este proceso de desarrollo que sea más importante que otra; se trata de partes de un proceso continuo, y si no se produce cada estadio normalmente, en su momento adecuado y con la cadencia correcta, se corta el desarrollo siguiente». Para muchos es claro que con la fecundación se inicia un camino que con el tiempo sólo sufre cambios cuantitativos y no cualitativos. No hay transición continua sino un salto no derivable con la fecundación. Desde ese momento lo que se da una continuidad única a lo largo de las diferentes fases de la vida. Lo importante no es que no exista ningún corte claro. Las transiciones en los colores o entre el día y la noche no son claras. Lo fundamental es la existencia continua de un mismo y único ser que tiene un futuro con posibilidades abiertas, con posibilidades no realizadas que pertenecen a la historia vital de un ser humano del mismo modo que el presente y el pasado. Ese futuro por delante es algo más elevado que el pasado que ya no es y que su presente que es un paso hacia ese futuro.

5- Cohesión interna y coordinación. Hay una estricta dependencia de partes entre sí: células con células, tejidos con tejidos, órganos con órganos ${ }^{41}$. Esto supone la existencia de una cierta estructura. Hay una unidad en la totalidad. No todas las células son iguales. Muy temprano ya unas formarán parte de lo que será del embrión y otras de lo que será la placenta. Los primeros días son una secuencia coordinada y una interacción de actividades moleculares y celulares bajo el control del nuevo genoma que, a su vez, es moldeado por una cascada ininterrumpida de señales transmitidas de una célula a otra, y desde el ambiente interno y externo a cada una de las células, y dentro de estas, desde el citoplasma al núcleo. Un número elevado de genes reguladores del nuevo genoma (miles) asegura el tiempo exacto y el lugar preciso y la especificidad de los eventos morfogenéticos. Por eso el embrión no es un montón de células sino un conjunto de células integradas dentro de un único proceso dinámico.

El embrión preimplantatorio no es un simple aglomerado de células. Es necesario aceptarlo como un organismo viviente capaz de desarrollarse con un futuro por delante y que puede alcanzar un desarrollo adulto en condiciones apropiadas. Esto requiere una percepción holística del embrión. Del mismo modo que ante unas cuantas células malignas sentimos que pueden amenazar nuestra vida y al verlas por el microscopio no son simplemente un pequeño montón de células, ocurre lo mismo con la percepción microscópica de un embrión humano ${ }^{42}$. No podemos reducir el ser humano al ser humano adulto.

\footnotetext{
formados. En genética esto se denomina «efecto cascada». Por tanto, la información en la célula cigoto "provoca una cascada" hasta completar el desarrollo embrionario...A pesar de que la información en el cigoto humano puede dirigir la absorción de moléculas de la madre, eso difícilmente significa que las moléculas maternas, o de la madre misma, determinen la verdadera naturaleza del embrión» (S. Moore. Citado en $\mathrm{D}$. Nutwell (1993), "Scientific and Philosophical Expertise: An evaluation of the arguments on "Personhood" ", The Linacre Quarterly 60/1, 27).

${ }^{41}$ Serra, A. (1989), "El embrión humano, ciencia y medicina», en Abel, F., Boné, E. y Harvey, J. (eds.) (1989), La vida humana. Origen y desarrollo. Madrid y Barcelona: Universidad P. Comillas e Instituto Borja de Bioética, p. 45.

42 Schockenhoff, E. (2012), Ética de la vida. Barcelona: Herder, p.543.
} 
Para algunos autores es relevante la distinción de Zubiri entre personeidad (carácter de sus estructuras fundamentales) y personalidad (lo que el ser humano va construyendo a sí mismo a lo largo de la vida). Para ciertos autores el embrión desde el comienzo es persona pues tiene constituida su personeidad y tiene la tarea de construir su personalidad en el desarrollo de su vida.

6- Desde la fecundación, el embrión tiene toda la información genética necesaria para ser persona adulta: sólo falta desplegar su potencialidad. No es un ser humano en potencia. Es un ser humano actual con potencialidades que se irán actualizando. Es un sistema abierto en continuo intercambio de materia, energía e información. Como los adultos que no tienen todo y sobreviven en intercambio con el medio. El embrión no permanece a través del cambio, sino que cambia para seguir viviendo. El embrión no se desarrolla hacia la condición de hombre, sino desde el principio como hombre. No es una cosa, ni algo, sino «alguien» que dirá «yo». Richard Hare aplica la regla de oro al embrión: "debemos actuar frente a otros del mismo modo como celebramos que se haya actuado con nosotros ${ }^{43}$. Solo somos porque fuimos embriones. Hay una relación ininterrumpida de nuestra situación actual con respeto a las etapas iniciales de nuestra vida. Hay una obligación de protección de la dignidad humana que mutuamente nos reconocemos todos en el origen. Los embriones se encuentran en una situación en la que nosotros nos encontramos antes. Hay una obligación de reciprocidad de respetar las oportunidades de nuestros descendientes igual que respetaron en su momento nuestras vidas $^{44}$. No son las cualidades las que otorgan derechos al embrión preimplantatorio sino su capacidad de ser sujeto moral, su capacidad moral, que se adquiere en un devenir natural, en un proceso que vincula vitalmente la adultez con los estadios embrionarios más tempranos.

7- Teleología frente a totipotencia. Las células del embrión preimplatatorio no son estrictamente totipotentes. Son totipotentes sólo después de haber sido separadas del embrión. Integradas dentro del embrión son parte de él ${ }^{45}$. Tienen un telos dentro de esa estructura. Ya en los primeros días están parcialmente definidas para ser embrión o placenta. «El lugar de la penetración del espermatozoide en el óvulo determina la polaridad del embrión, el plano de la primera división celular definiendo las dos mitades embrionaria y abembrionaria del futuro blastocito... El destino de cada célula está sesgado con una finalidad (telos) en su desarrollo, pero dada la plasticidad de los blastómeros puede darse una reprogración ${ }^{46}$. Hay una finalidad, forma final, que se va alcanzando gradualmente. El embrión antes de la implantación posee ya la potencialidad de desarrollarse desde este contexto vital. No cabe aplicar la distinción entre la bellota y el roble o el huevo y el pollo. El proceso de hominización desde el principio contiene la condición de un sujeto que se desarrolla procesualmente.

Aristóteles distingue entre dos tipos de posibilidad (dynamei), entre lo que sólo es posible en el pensamiento y lo ya predispuesto para ser, lo posible que está por devenir real. Pone el ejemplo de la casa: una casa en la imaginación de un hombre que quizás quiera edificarla es distinta de la que existe en los planos del arquitecto y en los esbozos

43 Hare, R. (1990), «Abtreibung und die Goldene Regel», en LeIst, A. (ed.) (1990), Um Leben und Tod, Frankfurt del Meno, p. 138.

44 Para una reflexión sobre la reciprocidad no estricta entre seres humanos es interesante la reflexión: MacIntyre, A. (2002), Animales racionales dependientes. Barcelona: Paidos.

45 MAY, W. (1992), "The moral status of the embryo», The Linacre Quarterly 59, pp. 80-81.

46 Nuñez de Castro, I. (2008), De la dignidad del embrión. Madrid: Universidad P. Comillas, p. 94. 
de los obreros que van a construirla. Sólo este segundo tipo de potencialidad lleva en sí mismo su arché, el principio de su devenir. Si no hay impedimentos externos, ese potencial llegará a ser por sí. Aristóteles lo ejemplifica con el niño engendrado por sus padres que es distinto del niño imaginario que alguna vez imaginan engendrar. El primero lleva en sí todas las capacidades para su futuro $\operatorname{ser}^{47}$.

También es muy sugerente la reflexión de Lejeune cuando afirma que el cigoto humano es la célula más determinada y especializada de todas, pero que va perdiendo progresivamente su habilidad para usar toda su información: «Una célula especializada del riñón no puede ser estimulada para llegar a ser un completo ser humano, no porque no posea toda la información necesaria (que la tiene), sino porque el resto de la información que no necesita para ser célula renal ha sido "silenciada"...Por ello, el cigoto no es algo indeterminado. Es quien representa la mayor riqueza del contenido humano y de la información utilizable...y decidirá que reacciones y formaciones tendrán lugar. Dirigirá todos los procesos durante el proceso embriológico completo» ${ }^{48}$.

8- Dignidad, vulnerabilidad y fragilidad. La vulnerabilidad comporta una llamada a nuestra responsabilidad en el cuidado. Para muchos autores es importante subrayar la inseparabilidad entre desvalimiento biológico y excelencia. Cuando más se asciende en la escala filogenética se da un mayor desvalimiento y vulnerabilidad. La dependencia del ser humano de los progenitores supone en la mayoría de los casos casi un cuarto de la vida. Ya Gabriel Marcel en su estudio sobre La dignité humaine señala que la dignidad humana aparece más clara en su desnudez y debilidad, en el niño, en el anciano, en el pobre. Para Levinas, el otro se impone con su fragilidad y, por eso, soy responsable del otro. Desde esta perspectiva se comprende que una buena sociedad será aquella que sea capaz de acoger a ese ser frágil que es el embrión humano. Juan Pablo II en este mismo sentido afirma: «Defendiendo al embrión, la sociedad protege a todo el hombre que reconoce en este pequeño ser sin defensa lo que él fue al comienzo de su existencia. Más que ninguna otra, esta fragilidad humana exige, desde el principio la solicitud de la sociedad que se honra garantizando el respeto de sus miembros más débiles ${ }^{49}$.

Hennaux también realiza una reflexión semejante. «El único modo de ser justo con la vida es respetar al más pequeño de los vivientes», al más vulnerable ${ }^{50}$. La sociedad y cada uno de sus miembros tienen el deber de acoger a los más frágiles. No existen seres humanos no personales. No se puede aceptar que discapacitados psíquicos no sean personas.

Frente a quienes ven la capacidad de vida independiente, la capacidad de tomar alimentos, de respirar o de hablar como fundamento de la protección, otros consideran la dependencia del embrión de la madre, que le ofrece protección y alimento, como el verdadero fundamento para una mayor protección. ¿No son los dependientes y vulnerables los que necesitan una mayor protección? ¿No necesitamos todos un mínimo de protección para existir? La dependencia continúa durante mucho tiempo en la vida humana. Incluso es difícil poder mantener la independencia y la madurez sin la vinculación de la amistad, de la familia, de la sociedad, etc.

\footnotetext{
47 Aristóteles, Metafísica, cap. 7, 1048b35-1049a15.

48 Nutwell, D. (1993), "Scientific and Philosophical Expertise: An evaluation of the arguments on "Personhood" ", The Linacre Quarterly 60/1, 28. La clonación de Dolly contradice lo aquí señalado.

49 JuAn PABlo II, «Audiencia al Grupo de trabajo sobre el Genoma humano», 20-11-1993, Ecclesia, nº 2663, 18 de diciembre de 1993, 21.

50 Hennaux, J.-M. (1993), Le droit de l'homme à la vie de la conception á la naissance, Bruxelles: IET, 28.
} 
Que una característica de la especie humana sea la racionalidad, no implica que todo miembro de la especie tenga el potencial de funcionamiento racional, tampoco es necesario que esté en acto sino que es suficiente que se presente como capacidad. Es lo que percibimos en la persona que duerme, en el discapacitado y en el feto ${ }^{51}$. De ajhí la importancia de educar la sensibilidad para apreciar el valor de la vulnerabilidad ${ }^{52}$. Sensibilidad embotada en una sociedad hipertecnificada y utilitarista que nos hace incapaces a muchos percibir ciertos valores.

9- Se presupone muchas veces una relación fuerte entre organización y presencia de órganos constatables. Pero el zigoto puede considerarse desde el punto de vista genotípico o fenotípico en cuanto a su morfología final macroscópica o a su morfología inicial microscópica. No se afronta la cuestión de la organización del genoma. Se privilegian normalmente en nuestras reflexiones los criterios morfológicos-anatómicos sobre los genómicos.

Por ello, se confunde con frecuencia ser humano y adulto. Un individuo puede pertenecer a la especie humana sin poseer ninguna propiedad morfológica de adulto. El zigoto no es un ser humano potencia, es actualmente un ser humano en potencia de ser adulto. Importancia del origen en la ciencia y no sólo en la historia. El embrión es un individuo humano real, no un potencial individuo humano ${ }^{53}$.

10- En relación y comunicación con la madre desde el primer momento. El cigoto «se comporta como un organismo abierto que recibe de la madre en el oviducto señales ectocrinas, además de las condiciones de oxígeno, temperatura, acidez, osmoticidad, nutrientes y fuerza iónica. La comunicación es recíproca, pues el embrión produce también hormonas y citocinas; la hormona leptina, segregada por el blastocito, es un marcador de la viabilidad del mismo $»^{54}$. Hay que ir en nuestro juicio moral más allá de la necesidad de reconocimiento. Algunos argumentan que el yo sólo se despierta por un tú que lo reconoce, por la aceptación de los padres. Es cierto que un bebé a quien no se le habla y a quien no se le da ninguna señal de amor genera una carencia afectiva que le puede llevar a la muerte. Todos debemos ser adoptados por un acto de reconocimiento parental. Pero el reconocimiento supone el valor de lo reconocido. El reconocimiento no constituye en persona. No es persona porque lo acogen sino que lo acogen porque es persona.

En estas reflexiones, muchas veces, no se valora la capacidad de relación existente en el embrión, su potencialidad de personalización. No hay que confundir relacionado y aceptado. Reducir la persona a la aceptación o el reconocimiento por los padres o la sociedad es un criterio frágil y voluble. Supone una reductiva concepción de la alteridad. Y además, ¿por qué limitar este enfoque a primeras etapas y no a después del nacimiento? ¿Desde que momento se le puede llamar hijo?

Desde los primeros días el embrión establece una especie de diálogo con la madre, bloqueando la producción de hormonas, enviando mensajes a la hipófisis y al hipotálamo, a los ovarios que van modificando el organismo materno que va reconociendo esta individualidad más allá del consentimiento consciente.

51 Lucas Lucas, R. (2000), «El estatuto antropológico del embrión humano», en AA.VV. (2000), Identidad y estatuto del embrión humano. Madrid: EIUNSA, p. 170.

52 López Azpitarte, E. (2003), Hacia una nueva visión de la ética cristiana. Santander: Sal Terrae, p. 122.

53 Serra, A. y Colombo, R. (1989), «Identitá e statuto dell'embrione umano: il contributo della biología», Medicina e Morale, 4, p. 146.

54 Núñez de Castro, I. (2008), De la dignidad del embrión. Madrid: Universidad P. Comillas, p. 94. 
La persona supone apertura, comunicación, comunión, ser-con (Jaspers, Marcel, Heidegger) pero la relación no es la que hace existir a las personas. La relación es reveladora del ser persona pero no constituye la persona.

Por otro lado, la dimensión intersubjetiva entra en la vida antes del nacimiento. Hay una interacción social, afectiva y lingüística con el niño que crece en el útero cuando la madre lo acaricia en el vientre, le habla, lo trata como un huésped en su cuerpo, cuando el médico lo examina y escucha los latidos de su corazón, cuando los padres lo cuentan a sus amigos y en el trabajo. En el lenguaje cotidiano, a un óvulo no nos referimos como «yo». En cambio todos entendemos cuando una madre dice a un hijo: «cuando estabas en mi vientre».

\section{ConCLusión}

Detrás de estas paginas hay una invitación a seguir pensando en profundidad dentro del marco concreto del embrión preimplantatorio el papel de la genética, el valor de la información extracigótica, el tema de las pérdidas, la cohesión entre las partes, la potencialidad, la individualidad, la teleología, la unidad y unicidad, la dependencia y la fragilidad, la continuidad y la novedad, lo puntual y lo gradual. Profundizaremos estas cuestiones en otro artículo.

Universidad Pontificia Comillas, Madrid

JAVIER DE LA TORRE

cbioetica@teo.upcomillas.es

[Artículo aprobado para publicación en diciembre de 2014]. 